\title{
Infrastructure and Growth
}

\author{
Yazid Dissou and Selma Didic
}

\section{Introduction}

While a high rate of economic growth does not necessarily reduce inequality or poverty, there seems to be a consensus among researchers and policy makers that continuous, rapid economic growth is required for poverty alleviation. Governments around the world are continually looking for new strategies to increase the ability of their economies to produce goods and services. In this light, over the last two decades, economists have developed more sophisticated models to evaluate the potential economic impacts of different supply-side policies that aim to raise the productive capacity of the economy. Specifically, alongside modelling the main factors of production - physical capital and labour - these models seek to account for the concurrent use of non-traditional inputs, such as public infrastructure and education, as key contributing factors to economic growth.

The seminal papers of Romer (1986, 1990), Lucas (1988) and Barro (1990) have paved the way for the emergence of an entire class of endogenous growth models that seek to explicitly endogenize human capital accumulation and infrastructure as two of the main arguments of the aggregate production function. In this chapter, we provide a literature review on the modelling of infrastructure and education in growth models. At the theoretical level, we present and evaluate different strategies employed by endogenous growth economists to model human capital and infrastructure. At the empirical level, we discuss the empirical findings regarding the effects of infrastructure and education on growth and poverty alleviation, particularly in developing countries.

The remainder of this chapter is organized as follows. In the section "Infrastructure in Growth Models", we provide a rationale for the introduction of infrastructure into growth models. We then compare and contrast the different modelling

Y. Dissou $(\bowtie) \cdot S$. Didic

Department of Economics, University of Ottawa, 9th Floor, FSS Building, 120 University,

K1N 6N5 Ottawa, ON, Canada

e-mail: ydissou@uottawa.ca; selma.didic@gmail.com 
strategies applied in a subset of macroeconomic literature that focuses on explaining endogenous growth in terms of public infrastructure. We conclude that section of the literature review with an assessment of the available empirical evidence regarding the effect of infrastructure on both growth and poverty alleviation with a special focus on developing countries. We use the same structure in the section "Education in Growth Models" with regards to education, and the final section provides our concluding remarks.

\section{Infrastructure in Growth Models}

\section{Theoretical Considerations}

\section{Overview}

Before discussing the various approaches used to model infrastructure in growth models, it may be useful to provide the rationale behind using infrastructure as an argument of an economy-wide production function. Three studies carried out by Aschauer in 1989 emphasized, among other things, the difference between productive and unproductive public expenditures, and helped catalyze an empirical debate on the effects of government expenditures on productivity. An interesting summary of the empirical results of this literature appears in the World Development Report (World Bank 1994), and shows that infrastructure seems to have no effect on economic growth in some cases and appears to generate returns in excess of $100 \%$ per year in other cases. These strongly contrasting findings may be explained, in part, by the extent to which researchers have successfully tackled various econometric challenges in estimating the relationship between infrastructure and growth. Both Estache and Fay (2009) and Gramlich (1994) pinpoint significant econometric problems arising in the macroeconomic time series models used to estimate aggregate production functions. These include: common trends in capital per capita and output per capita, omitted variable bias (e.g. energy prices), reverse causality, network effects, heterogeneity and poor data quality.

Reviewing the relevant studies in the literature on the infrastructure-growth nexus, and acknowledging that the connection between infrastructure and growth appears to vary across countries and over time as well as within countries and within sectors themselves, Estache and Fay (2009) suggest that increasing empirical agreement exists regarding the growth-enhancing effect of infrastructure. For instance, in a review of evidence produced by Romp and de Haan (2005, p. 6), 32 of 39 studies on OECD countries find a "positive effect of infrastructure on some combination of output, efficiency, productivity, private investment, and employment." Moreover, 9 of 12 studies on developing countries indicate a significant positive impact (Estache and Fay 2009, p. 15). In addition, by employing an econometric technique that accounts for biases arising from omitted variables and 
that explicitly accounts for the government budget constraint, Bose et al. (2007) find that government capital expenditures as a share of GDP are positively and significantly related to per capita income growth across a panel of 30 developing countries over the 1970-1980 period. However, current expenditures are shown to have an insignificant effect on growth in these countries over this timeframe.

In this context, it is important to highlight the various transmission mechanisms through which infrastructure affects growth. The most conventional channel, first described in Aschauer (1989) and Barro (1990), is that public infrastructure investments enhance private sector productivity. Indeed, Aschauer (1989) attributed the 1970s U.S. productivity slowdown to the lack of infrastructural investment. This direct productivity effect of infrastructure investment captures the idea that an increase in public capital stocks (relative to private capital) has a positive but decreasing impact on the marginal product of all factor inputs (such as capital and labour). Hence, the cost of production inputs falls and the level of private production increases. As Agenor and Moreno-Dodson (2006, p. 9) point out, "this scale effect on output may lead, through the standard accelerator effect, to higher private investment - thereby raising production capacity over time and making the growth effect more persistent."

Agenor and Moreno-Dodson (2006) identify two additional conventional channels through which infrastructure may affect growth, namely complementarity and crowding out effects. The first channel promotes growth through private capital formation. That is, public infrastructure raises the marginal productivity of private inputs, thereby raising the perceived rate of return on private capital and possibly also increasing private sector demand for physical capital. The second channel, crowding out, captures the idea that, in the short run, an increase in public capital stocks may displace or crowd out private investment. This negative crowding out effect of infrastructure may turn into a long-term negative effect if the decrease in private capital formation persists over time.

In addition to the three 'conventional' channels above, recent studies have also identified a variety of other channels through which public infrastructure may impact growth. Estache and Fay (2009) suggest that, in addition to the channels mentioned above, investment in public infrastructure can also impact investment adjustment costs, the durability of private capital, and both the demand for and supply of health and education services. In the same vein, Agenor and MorenoDodson (2006) argue that infrastructure may reduce investment adjustment costs via two channels: through complementarity between public capital and private investment and through the decreased costs associated with capital reallocation between sectors following a shock.

Maintaining the quality of public infrastructure may positively affect growth by improving the durability of private capital. That is, increasing government infrastructure maintenance spending allows the private sector to spend less to maintain its own capital and thus to allocate its investment capacity to other uses, thereby generating an additional growth effect. Better infrastructure is also found to improve access to health care and education. By improving health and education outcomes, the impact of public infrastructure on growth is magnified or 
compounded due to the interconnected relationship between education and health (Agenor and Moreno-Dodson 2006). Healthier individuals tend to study more, while more educated individuals also tend to be healthier.

Moreover, Agenor and Moreno-Dodson (2006) add labour productivity as another channel whereby public infrastructure indirectly increases growth. Better access to infrastructural facilities means that workers can get to their jobs more easily and perform their job-related tasks more rapidly. Other studies have also found evidence of various positive externalities induced by public infrastructure, including increased competitiveness, greater regional and international trade, expanded FDI, and finally higher profitability of domestic and foreign investment flows which raises investment ratios and boosts growth in per capita income (Fourie 2006; Fedderke et al. 2006; Richaud et al. 1999).

Hence, at the theoretical level, infrastructure could be modeled as having an effect on any given measure of output via two channels: directly as a production factor and indirectly by influencing total factor productivity (TFP). The general production function would take the following form:

$$
Y=A\left(K_{P U B}\right) f\left(K, L, K_{P U B}\right)
$$

where $Y$ is output, $K$ is private capital, $L$ is labour, $A$ is TFP and $K_{P U B}$ is public capital.

Still, modelling infrastructure in the context of endogenous growth has been based on a more restrictive production function, generally excluding the indirect impact of infrastructure via TFP. Such a modelling approach, motivated by Barro (1990), introduces government infrastructure expenditures as an argument of the production function, and is justified by reasoning that private inputs $(\mathrm{K})$ are not a close substitute for public inputs. However, his assumption that public expenditures is a flow variable brought a wave of criticism, starting with Futagami et al. (1993) who modified Barro's original model (1990) by considering productive public expenditures as a stock variable, much like private physical capital is.

We can distinguish between two theoretical approaches to modelling the impact of infrastructure on growth. The first treats government infrastructure expenditures as a flow variable which directly enters the production function. The second treats public infrastructure as accumulated capital, rather than as current flows, and thereby represents infrastructure as a stock variable in the aggregate production function.

\section{Modelling Infrastructure as a Flow Variable}

Barro (1990) models infrastructure in the context of a simple AK endogenous growth model. The two building blocks of his model are a production function that incorporates public services (an expenditure flows variable) as an input to private production, and a Ramsey equation that captures the representative 
consumer's optimization behaviour. For most of his analysis, he assumes a CobbDouglas production function:

$$
\begin{gathered}
y / k=\Phi\left(\frac{g}{k}\right) \\
y=A \cdot g^{\alpha} k^{1-\alpha} ; \quad 0<\alpha<1
\end{gathered}
$$

where $y$ is output per worker, $k$ is capital per worker and $g$ is the per capita quantity of government purchases of goods and services. $\alpha$ is the (aggregate) production elasticity of public services; the function also defines the share of public services in total output. Production is assumed to exhibit constant returns to scale with respect to the private stock of capital and the flow of public services provided by the government. Barro (1990) makes a theoretical assumption that the government is not engaged in production and does not own capital; rather, it buys a flow of output (e.g. services of highways, sewers, etc.) from the private sector. These services are paid for and made available to households and correspond to the input $g$. Moreover, Barro (1990) argues that it is the amount of government purchases per capita that matters since few government services are actually non-rival.

The second building block in the model is the consumption growth rate equation, derived from the utility-maximization problem of the infinite-lived household:

$$
\frac{\dot{C}}{C}=\frac{1}{\sigma}\left(f^{\prime}-\rho\right)
$$

where f' is the marginal product of capital.

The income tax rate is set to finance the chosen level of expenditure:

$$
g=T=\tau y=\tau k \Phi\left(\frac{g}{k}\right)
$$

where $T$ is government revenue and $\tau$ is the tax rate. By normalizing the number of households to unity, $g$ represents aggregate expenditures and $T$ aggregate revenues. This equation constrains the government to run a balanced budget.

Given the production function specified in Eq. 1, the marginal product of capital is:

$$
f^{\prime}=\Phi\left(\frac{g}{k}\right)\left(1-\Phi^{\prime} \frac{g}{y}\right)=\Phi\left(\frac{g}{k}\right)(1-\eta),
$$

where $\eta$ is the elasticity of $y$ with respect to $g$ (for a given value of $k$ ), such that $0<\eta<1$. Since income is taxed to provide for public services, Eq. 4 is modified as follows: 


$$
\gamma=\frac{\dot{c}}{c}=\frac{1}{\sigma}\left[(1-\tau) \Phi\left(\frac{g}{k}\right)(1-\eta)-\rho\right]
$$

Provided that the government sets $g$ and $T$ to grow at the same rate as $y, g / k$ and $\eta$, then $\gamma$ will be constant. As a consequence, in the steady state, ${ }^{1}$ per capita consumption, per capita output and per capita capital will grow at the same rate, a positive function of the marginal product of capital.

By differentiating Eq. 7 with respect to $\mathrm{g} / \mathrm{y}$,

$$
\frac{d \gamma}{d\left(\frac{g}{\gamma}\right)}=\frac{1}{\sigma} \Phi\left(\frac{g}{k}\right)\left(\Phi^{\prime}-1\right)
$$

Barro (1990) shows that the decision to invest in public infrastructure has two opposing effects: a positive one, where an increase in productive government spending increases the marginal product of private capital and thus generates sustained per capita growth; and a negative one, where an increase in financing of public infrastructure by taxing income reduces per capita growth. The negative effect dominates when government size is large, while the positive effect dominates when government is small.

In Barro's (1990) model, to maximize growth, the government must set the tax rate equal to the elasticity of the public services $g$ in aggregate production. In maximizing growth (Eq. 7) with respect to the tax rate $\tau$, the government must set $\tau^{*}=\Phi=\alpha$. In the context of the model, this condition not only corresponds to maximum growth, but it also maximizes lifetime utility or welfare. In other words, to maximize the national growth rate and social welfare, the government sets the optimal level of the income tax financing public services as a share of national income to be equal to the contribution of public services to aggregate output in a competitive economy (i.e. the elasticity of the public services $g$ in aggregate production). This result is crucially dependent on the Cobb-Douglas functional form used to represent technology.

This baseline approach to modelling infrastructure as a flow variable has been adopted and extended by several other authors. Some of these include Rivas (2003), Eicher and Turnovsky (2000), Yakita (2004), Ohdoi (2007), Chen and Lee (2007) and Park and Philippopoulos (2002). The main advantage of modelling infrastructure as a flow variable is that it produces highly tractable models (Fisher and Turnovsky 2013). Agenor (2007) observes that the flow specification generates results that are not qualitatively very different from studies employing the stock specification of infrastructure. However, it has been argued that as long as one is interested in modelling the impact of infrastructure on growth, the stock variable specification may be more appropriate or plausible. One of the reasons for this is that specifying infrastructure as a flow variable within the production function

\footnotetext{
${ }^{1}$ The economy is always in the steady state, i.e., there are no transitional dynamics.
} 
implies that only newly established roads or buildings raise the level of private production, and that previously accumulated capital does not contribute to this increase.

As Fisher and Turnovsky (2013, p. 399) write, "the flow specification ... is open to the criticism that insofar as productive government expenditures are intended to represent public infrastructure, such as roads and education, it is the accumulated stock, rather than the current flow, that is relevant.'Furthermore, another criticism of the flow specification approach captures the idea that it may not be realistic to describe government expenditures on infrastructure as a non-rival good like aggregate knowledge. Public infrastructural expenditures may not always be complementary to private capital in the aggregate production function, and instead may be rival at the level of the aggregate economy through crowding out effects.

\section{Modelling Infrastructure as a Stock Variable}

Futagami et al. (1993) combine Barro's (1990) model with the assumption that government spending does not influence the aggregate production function directly, but only indirectly via the stock of public capital. By including two stock variables, Futagami et al. (1993) bring transitional dynamics into the model in contrast to the endogenous growth models employing the flow specification. The main finding of the Futagami et al. (1993) study is that Barro's (1990) result about optimal fiscal policy remains valid in the steady-state equilibrium even if government services are proportional to the stock of public capital (rather than capital expenditure flows), but not in the development transition phase. That is, when transitional dynamics are introduced into the model, the tax rate that maximizes welfare is found to be lower than the tax rate that maximizes growth under a log-liner utility function.

Futagami et al.'s (1993) modelling strategy of incorporating public infrastructure into an endogenous growth model differs from that of Barro (1990) in that government services are now accumulated like physical capital. In other words, the stock specification of infrastructure now requires the introduction of a government services accumulation equation:

$$
\dot{\mathrm{g}}=\tau y-\delta g
$$

where $\delta \geq 0$ is the rate of depreciation, and g now stands for government services derived from public capital. The Cobb-Douglas production function exhibits constant returns to scale with diminishing returns with respect to each factor, the consumption growth equation is given by the Ramsey rule, and the flat-rate income tax that finances the chosen level of public expenditure remains as in the Barro (1990) model (i.e. Eqs. 2, 3, 4, and 5 of the Barro (1990) model). Integrating (9) backwards yields: 


$$
\dot{\mathrm{g}}=\frac{\tau y}{g+\delta}
$$

instead of Eq. 5 of the Barro model. Equation 10 of the Futagami et al. (1993) model now enters the production function (2) and the output growth rate Eq. 7. Because $g$ grows at a constant rate in the steady state, the expansion factor $1 /(g+\delta)$ does not change the underlying results of the utility maximization problem, such that the government, in maximizing growth, still chooses $\tau^{*}=\Phi$ (Tsoukis and Miller 2003). Hence, the steady-state growth-maximizing tax rate is equal to the production elasticity of government services, $g$, as in Barro (1990).

However, Futagami et al. (1993) find that maximizing the growth rate of the economy is not equivalent to maximizing social welfare. They argue that in an endogenous growth model with transitional dynamics and log-linear utility, "reducing the tax rate from the rate which attains the maximum national growth rate increases the agents' lifetime welfare" (Futagami et al. 1993, p. 622).

Subsequent studies, such as Fischer and Turnovsky (1998), Rioja (1999), Turnovsky (2004), Tamai (2007), Kalaitzidakis and Kalyvitis (2004), Tsoukis and Miller (2003) and Zhao and Kanamori (2007) have extended the basic Futagami et al. (1993) framework of modelling infrastructure as a stock variable. Following the tradition of Barro (1990) and Futagami et al. (1993), Tsoukis and Miller (2003) also seek to obtain the rule of optimal fiscal policy.

In contrast to previous studies that assumed that public services are derived from either flow expenditures or the stock of public capital, Tsoukis and Miller (2003) consider the case where public services are derived from both public capital stocks and expenditure flows. They also introduce private capital adjustment costs into their analysis. Tsoukis and Miller (2003) consider the following production function:

$$
Y=K^{1-\varphi}\left(P^{\alpha} H^{1-\alpha}\right)^{\varphi}, \quad 0<\varphi, \quad \alpha<1
$$

where $\mathrm{K}$ and $\mathrm{P}$ are respectively the stocks of private and public capital and $\mathrm{H}$ is the flow of non-capital public expenditures. The term in brackets is a Cobb-Douglas production function of public services which generates constant returns to scale in the aggregate economy and provides a mechanism for endogenous growth. The government budget constraint is specified as follows:

$$
\dot{P}=(\gamma-h) Y
$$

where $\gamma$ is now the tax rate. Total government expenditures is the sum of public investment $(x)$ and non-capital public expenditure $(h)$ as a share of output. Their study suggests that taxation has a negative effect on private returns to capital, while the effects of $h$ and $x$ are positive because spending on public investment and flow services enhances productivity. Tsoukis and Miller (2003) proceed to derive the optimal policies for growth. They find that the Barro rule, $\tau^{*}=\alpha$, used to maximize steady-state growth, also applies in a framework where public services are 
derived from both public capital and flow services. However, according to Tsoukis and Miller (2003) and in line with the findings of Futagami et al. (1993), this rule is too high for welfare maximization.

As argued in Zhao and Kanamori (2007), most of the existing endogenous growth models which explicitly account for public infrastructure fail to consider the external effects of this infrastructure on consumption. In other words, the studies reviewed above, as well as many others, fail to account for the positive effect of public services on household utility. Zhao and Kanamori (2007) also observe that the flow specification of infrastructure is inappropriate since "what contributes directly to production and utility is the service flow of public infrastructure produced by capital." As a consequence, they include the stock of public infrastructure in both the household's objective utility function and the private production function.

On the production side, the authors allow the service flow provided by public infrastructure $K_{g t}$ to be an argument of the production function:

$$
y_{i t}=A\left(k_{i t}\right)^{1-\alpha}\left(K_{g t}\right)^{\alpha}
$$

Private capital is accumulated according to the following motion equation:

$$
\dot{k}=(1-\tau) y_{i t}-(\delta+n) k_{i t}-c_{t}
$$

On the consumption side, households gain utility from both consumption and spillover effects of service flows of public infrastructure:

$$
U=U\left(c_{t}, K_{g t}\right)=\log \left(c_{t}, K_{g t}\right)
$$

The government in the model is only assumed to provide public infrastructure, which is consumed by households as consumers and as producers without any direct payment. The production function of newly produced infrastructure (the infrastructure flow) is represented as:

$$
I_{g t}=N L_{i t} A_{g}\left[(1-\varphi) \tau y_{i t}\right]
$$

The infrastructure stock accumulation equation is given by

$$
\dot{K}_{g t}=N L_{i t} A_{g}\left[(1-\varphi) \tau y_{i t}\right]-\delta_{g} K_{g t}
$$

Maximizing lifetime utility of this infinitely lived household leads to the following consumption growth and private capital growth equations, which describe the transitional dynamics 


$$
\begin{aligned}
& \frac{\dot{c_{t}}}{\bar{c}_{t}}=\left[(1-\alpha)(1-\tau) A\left(\frac{k_{i t}}{K_{g t}}\right)^{-\alpha}-(\delta+\rho)\right] \\
& \frac{\dot{k_{i t}}}{k_{i t}}=(1-\tau) A\left(k_{i t}\right)^{-\alpha}\left(K_{g t}\right)^{\alpha}-(\delta+n)-\frac{c_{t}}{k_{i t}}
\end{aligned}
$$

Clearly, the household consumption growth rate increases with public infrastructure. Since both capital and consumption grow at a constant rate in the steady state, we have:

$$
\begin{gathered}
k_{i t}^{*}=[(1-\alpha)(1-\tau) A /(\delta+\rho)]^{\frac{1}{\alpha}} K_{g t} \\
c_{t}^{*}=[[(\delta+\rho) /(1-\alpha)]-(\delta+n)][(1-\alpha)(1-\tau) A /(\delta+\rho)]^{\frac{1}{\alpha}} K_{g t}
\end{gathered}
$$

The steady-state per capita capital equation implies that consumption growth is positively related to infrastructure accumulation and is negatively related to the tax rate, the capital depreciation rate and the time preference rate.

In relation to the impact of infrastructure on investment, Zhao and Kanamori (2007) suggest that it would be possible for the individual household as a producer to produce up to the point where marginal product exceeds marginal cost if there is overinvestment in public infrastructure, which leads to an above normal profit for producers. The authors also state that the government should decide on the amount of infrastructure as well as the level of tax revenues required to finance the infrastructure provided.

So far, a common feature of the modelling strategies that employ the stock specification of infrastructure has been to assume a constant depreciation rate of public capital. Kalaitzidakis and Kalyvitis (2004) modify this assumption by introducing public capital maintenance expenditures. They begin with the following production function of representative firm $i$,

$$
Y_{i}=K_{i}^{\alpha}\left(h L_{i}\right)^{1-\alpha}, 0<\alpha<1
$$

where $K_{i}$ denotes the stock of private capital and $L_{i}$ the labour used by firm $i$. Labour productivity, $h$, is a function of the existing aggregate stock of per worker private capital $K$, and per worker public capital $K_{g}$, such that:

$$
h=\frac{K^{\beta} K_{g}^{1-\beta}}{L}, 0<\beta<1
$$

where $L$ is the total labour force. With $\beta=0$, one obtains the standard Barro (1990) endogenous growth model with productive public expenditures. The private capital accumulation equation is specified as: 


$$
\dot{K}=I-\delta_{k} K
$$

where $I$ denotes gross private investment. Furthermore, the transformation of output into private capital involves adjustment costs. The cost of investment faced by local firms is:

$$
\Psi(I, K)=\left(1+\frac{\varphi}{2} \frac{I}{K}\right) I
$$

where $\varphi>0$ is an adjustment cost parameter.

The novelty in Kalaitzidakis and Kalyvitis (2004) is that they allow the depreciation rate to vary with maintenance expenditures. They define public capital maintenance as "the deliberate utilization of all public resources which preserve the operative state of public capital goods" and specify the following public capital accumulation equation:

$$
\dot{K}_{g}=G-\delta_{g}\left(\frac{M}{Y}\right) K_{g}, \text { with } \delta_{g}^{\prime}(.)<0
$$

where $\delta_{g}$ is the public capital depreciation rate and $G$ denotes public investment for 'new' public capital. The public capital depreciation rate is assumed to be a function of public capital maintenance expenditures as a share of aggregate output. It depends negatively on maintenance expenditures $M$ and positively on usage measured by aggregate economic activity $Y$. The government budget constraint is then:

$$
G+M=\tau Y
$$

It is clear that this government finances its total expenditures ('new' public investment plus maintenance) through taxes imposed on total output produced by firms. Furthermore, the authors define the share of total government expenditures respectively going toward maintenance and 'new' investment as $\mu$ and $(1-\mu)$ :

$$
M=\mu \tau Y \text { and } G=(1-\mu) \tau Y
$$

The solution to representative firm i's infinite horizon profit maximization problem yields a system of two differential equations describing the dynamics of the economy:

$$
\frac{\dot{z}}{z}=\delta_{g}(\mu \tau)+\left(\frac{q-1}{\varphi}\right)-(1-\mu) \tau z^{\omega}-\delta_{k}
$$




$$
\dot{q}=\left(r+\delta_{k}\right) q-(1-\tau) \alpha z^{\omega-1}-\left(\frac{(q-1)^{2}}{2 \varphi}\right)
$$

where $\omega=\alpha+\beta(1-\alpha)<1, z$ denotes the private-to-public capital stock ratio, $q$ is the shadow value of private capital stocks and $r$ is the real interest rate. Since the dynamic system of the economy is nonlinear, the authors linearize these two dynamic equations near the steady state and then analyze how maintenance expenditures and taxes affect long-run growth.

The authors find that "the government can improve the growth rate of the economy by reducing (increasing) the share of maintenance expenditure in total expenditure if it is set at a high (low) level" as the tax rate is already set at the steady-state level. Concerning the changes in the tax rate, the authors consider two cases. In the first case, the economy has excess tax revenues, which reduces the marginal product of private capital and hinders private capital accumulation. A tax reduction in this case would stimulate private investment and growth until the economy reaches a new steady state described by a higher private-to-public capital ratio. In the second case, the economy has a shortfall of tax revenues, by definition, such that an increase in the tax rate would reduce private capital accumulation and increase public capital accumulation. The economy reaches a new steady state characterized by higher growth and a lower private-to-public capital ratio.

In contrast to Barro (1990), Futagami et al. (1993) and Tsoukis and Miller (2003), Kalaitzidakis and Kalyvitis (2004) find that the optimal tax rate to maximize long-run economic growth is larger than the production elasticity of public capital when maintenance expenditures are incorporated into the infrastructure-led endogenous growth model:

$$
\tau^{*}=\frac{1-\omega}{1-\mu^{*} \omega}
$$

They explain this finding as resulting from the beneficial impact that infrastructure maintenance spending has on public capital formation, which provides the economy with an additional benefit derived from the longer durability of public capital.

Regardless of whether the modelling strategy employs a stock or a flow variable approach to measuring infrastructure, there seems to be a common tendency within the theoretical literature to ignore the indirect impact of infrastructure via TFP. In other words, the common approach used to analyze the effects of public capital on output assumes that infrastructure only affects output directly as a production factor. 


\section{Empirical Models: Estimating the Effect of Infrastructure on Growth}

\section{Overview}

In the next section, we review the empirical evidence regarding the effect of infrastructure on economic growth and its effect on poverty and income distributions in developing countries. As previously mentioned, there seems to be an increasing consensus around the idea that infrastructure, by raising labour productivity and lowering production and transaction costs, is beneficial for economic growth.

According to the findings of numerous studies, economic growth may just be the single most important determinant of poverty reduction (e.g. Lopez and Serven 2004; Dollar and Kraay 2002; Fanta and Upadhyay 2009). Through its positive contribution to economic growth, infrastructure investment presents a powerful tool that policy-makers can use to reduce poverty and raise living standards. At the same time, investments in transport, water, sanitation, irrigation, telecommunications and energy can directly improve the welfare of the poor simply by providing access to basic needs.

Ali and Pernia (2003) suggest that the benefits of infrastructure development for poverty reduction are manifested through two main channels: through the effect on income distribution (the direct channel), and through the effect on economic growth (the indirect channel). The 'income distribution effect of infrastructure' brings about improved employment and earnings prospects for the poor as a result of growth in the non-agricultural sectors of the economy and by increasing productivity in both the agricultural and non-agricultural sectors. By encouraging further economic activity, these productivity and employment gains drive the economic growth process leading to the so-called 'infrastructure growth effect'. Ali and Pernia (2003) provide a neat diagrammatical summary of the links running from infrastructure investments to real income and consumption of the poor, and consequently to poverty reduction (Fig. 1):

Indeed, the importance of the agricultural sector for growth, particularly in poorer developing countries, is widely recognized. Based on a sample of 40 developing countries, Thirtle et al. (2001) find the elasticity of poverty reduction with respect to agricultural productivity growth to be between 0.62 and 1.3 , namely, the percentage of those living below the dollar a day poverty line falls by somewhere between $0.62 \%$ and $1.3 \%$ points for every percentage point increase in agricultural productivity. The findings of Bravo-Ortega and Lederman (2005), reported in the World Development Report (World Bank, 2007), indicate that, in developing countries, an increase in GDP brought about by an increase in agricultural labour productivity raises the incomes of the poorest quintile by an average of 2.9 times more than an equivalent increase in GDP arising from non-agricultural labour productivity. 


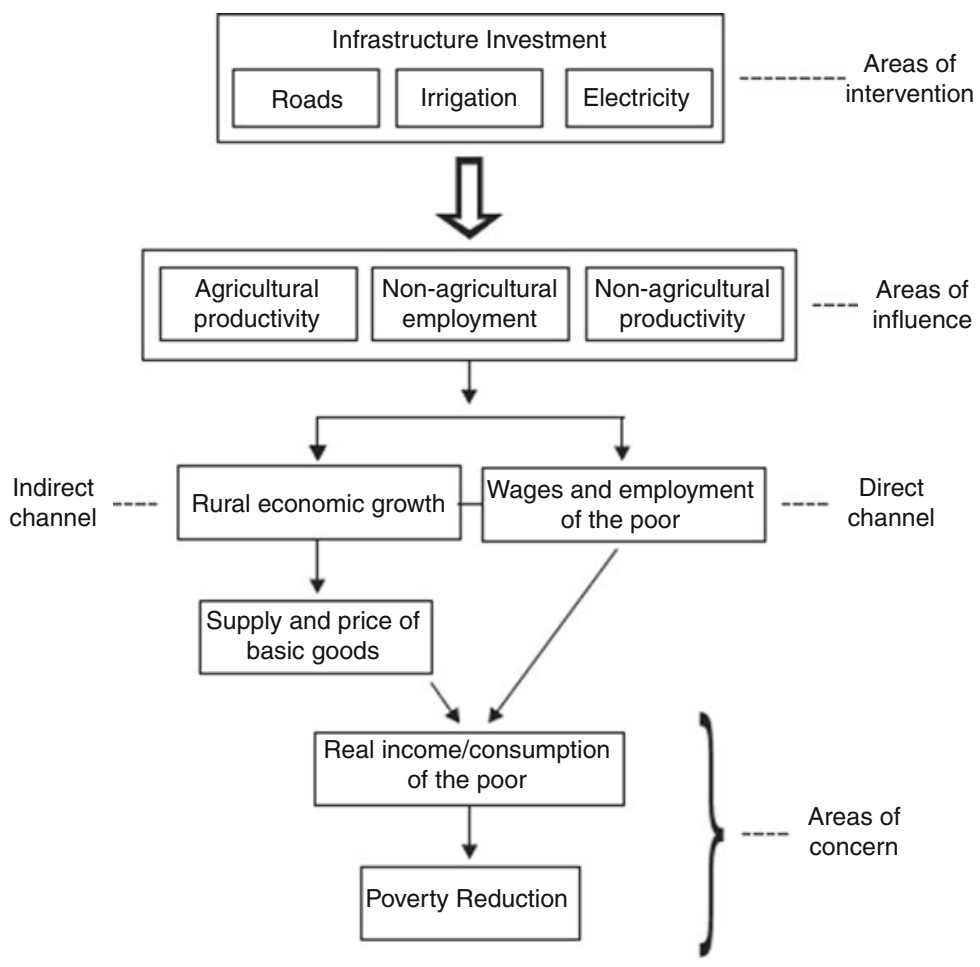

Fig. 1 Simple analytical framework depicting the links between infrastructure and poverty reduction (Source: Ali and Pernia (2003))

Hanmer and Naschold (2000) find that agricultural productivity growth has the greatest poverty-reducing effect in countries with the lowest levels of development, such as in Sub-Saharan Africa and South Asia. However, in more developed and urbanized regions of the world, such as East Asia and Latin America, growth originating in sectors other than agriculture seems to have larger poverty reduction effects (Hasan and Quibria 2004). In any case, the importance of agriculture for the poorest countries in the world is not solely related to its ability to reduce poverty, but also to its ability to drive broad-based economic growth reflecting agriculture's strong linkages with the rest of the economy.

Clearly, this evidence points to the observation that certain investments, particularly those aimed at developing and improving infrastructural facilities can positively impact agricultural and non-agricultural productivity growth. Such investments have the potential to help reduce poverty in developing economies through their spillover effects. Yet, little empirical attention has been paid to the channels through which infrastructure influences economic growth and poverty in developing countries. For the most part, econometric cross-country regression studies fall short of providing a detailed picture of the various linkages existing 
between infrastructure development, economic growth, and poverty alleviation. However, these studies do provide useful insights into the magnitude and statistical significance of the effect of infrastructure on poverty and growth.

Next, we will take a look at some of these empirical studies which investigate the link between infrastructure, growth and poverty in developing countries. Most of these studies apply an individual, "physical" measure of infrastructure and thus attempt to gauge the economic and growth impacts of investments in a variety of infrastructure subsectors, particularly transport, energy and irrigation.

\section{Empirical Studies on the Impacts of Road Infrastructure on Growth and Poverty}

A substantial number of empirical studies find that investments in road (transportation) infrastructure contribute to both economic growth and poverty alleviation. These studies confirm that road infrastructure can have a direct and an indirect effect on reducing poverty in developing countries, although the extent of benefits derived can vary by income level. But while many studies suggest that road infrastructure development may be the single most important determinant of growth and poverty alleviation in developing countries, its presence does not appear to guarantee these outcomes. An increasing number of empirical studies in this area find that the effect of road infrastructure on economic growth and poverty alleviation is at least somewhat contingent on complementary investments, such as investments in human capital.

Kwon (2005) is one study that provides evidence on the direct and indirect contribution of road infrastructure to poverty alleviation. He finds that the positive impact of roads on poverty reduction in Indonesia resulted from broader economic growth and in particular improved wages and employment of the poor. The author uses 1976-1996 Indonesian provincial level panel data and splits samples to examine cross-sectional differences between provinces with good and bad access to transportation infrastructure via an instrumental variable approach (where good access is defined as above average road density ${ }^{2}$ and bad access is defined as below average road density).

First, the author finds that road investments significantly increased GDP growth in provinces with both good and bad access to roads, with every $1 \%$ of provincial GDP growth leading to a $0.33 \%$ decline in poverty incidence in provinces with good roads and a $0.09 \%$ decline in those with bad roads. Kwon $(2005$, p. 3) writes that this finding suggests that "the accumulation of road capital has a nonlinear contribution to poverty alleviation. As road capital is accumulated, the link between economic growth and poverty reduction becomes stronger and, in this way, roads produce a more efficient linkage between them."

\footnotetext{
${ }^{2}$ Road density is measured as the length of roads in kilometers per thousand square kilometers.
} 
Second, the author finds that road infrastructure can contribute directly to reducing poverty, independent of its effect on GDP growth in each of two provinces. Compared with other types of government investments, such as those in education and health, Kwon's (2005) study reveals that the poverty rate is most sensitive to public investment in roads, such that a $1 \%$ increase in road investment is associated with a $0.3 \%$ drop in poverty incidence over 5 years. This is because provincial roads were found to directly improve the wages and employment of the poor in Indonesia. This finding leads the author to observe that road infrastructure has explanatory power on its own with regards to poverty incidence.

Fan et al. (2002) study is one of the rare econometric studies that attempts to trace the linkages and channels through which public investment in infrastructure operates to reduce poverty. They develop a simultaneous equations model to estimate the effects of different types of public infrastructure spending on agricultural growth and rural poverty in China using 1970-1997 provincial level data. The authors address the endogeneity problem by using a two-step procedure to estimate the full system of equations based on the maximum-likelihood technique. The first step involves estimating all equations other than the poverty equation, which is estimated in the second step using the predicted values of the independent variables of interest. Their results reveal that government spending on rural road infrastructure has a significant impact on poverty reduction not only through improved agricultural productivity, but also through increased non-agricultural employment opportunities and increased rural non-agricultural wages.

More specifically, the estimated elasticity of poverty with respect to agricultural labour productivity is found to equal -1.13 . This elasticity equaled -0.56 with respect to non-farm income and -0.86 with respect to non-agricultural employment. Estimated (significant) elasticities with respect to road density in rural areas are 0.80 for agricultural labour productivity, 0.15 for rural non-agricultural wages and 0.10 for non-agricultural employment. In addition to road density, rural non-agricultural wages are also found to be affected by agricultural labour productivity: this elasticity is 0.87 and statistically significant.

Some studies have attempted to estimate the marginal returns to poverty reduction and sectoral GDP associated with public investment in roads. In contrast to Kwon (2005), Fan et al. (2002) find that road investment ranks third, after education and R\&D investment, in terms of its poverty-reducing effect. Still, the poverty impact of road investment is found to be substantial: for every 10,000 yuan invested in rural road infrastructure, an average of 3.2 persons are brought out of poverty. With respect to the growth effect, road investment ranked second generating some 8.8 yuan of rural GDP for every yuan invested, slightly below the returns obtained for R\&D investment. Among other types of investments, road investment appeared to produce the largest returns to rural non-farm GDP, at 6.7 yuan for each yuan invested.

Mu and van de Walle (2007) investigate the impact of a rural road rehabilitation project funded by the World Bank and implemented in Vietnam between 1997 and 2001. The objectives of the project were to develop local market activities and encourage economic development by targeting road improvements in poor 
communities. The authors assess the short-term (1997-2001) and medium-term (1997-2003) impacts of the rural road rehabilitation project on a set of outcome variables closely related to local market development. In order to control for endogeneity arising from the communities' inclusion in the project, the authors apply a double difference estimator with propensity score matching under the assumption that time variant selection bias may affect the results.

A notable finding of the Mu and van de Walle (2007) study suggests that road improvements can exert an almost immediate impact on poverty reduction through the human capital channel. Specifically, among the 14 outcome variables considered in the study, the primary school completion rate was the only variable for which road improvements seemed to have a statistically significant impact in the short run. By 2001, the primary school completion rate rose by $15-25 \%$ in communities included in the road rehabilitation project, and this impact appeared to only strengthen over time. The authors rationalize that roads encouraged students to complete their primary school education by providing them with access to secondary schools.

Significant impacts on other variables related to local market development emerged only in the medium-term. Mu and van de Walle (2007) find that communities that benefitted from the road rehabilitation project experienced larger increases in the availability of services and markets compared with those that did not. These changes further impacted the employment and livelihood patterns of households living in the beneficiary communities, such that the share of households relying on agriculture as the main source of income declined while the share relying on the services sector increased.

In fact, Mu and van de Walle (2007) demonstrate that the strongest development of markets was found in those communities which were characterized by an initially low level of market development. The magnitude of the impacts of road improvements on a host of market development variables considered in the study was generally larger for the poorest of the communities included in the project. This finding suggests that the extent of benefits derived from road infrastructure development can vary with income level.

Lokshin and Yemtsov (2005) develop this idea further. Using combined household and community level data and applying a propensity score matched differencein-difference comparison between project beneficiaries and a control group, this study examines the average impact of a project that, among other goals, aimed to improve the road and bridge infrastructure in rural Georgia between 1998 and 2001.

Their results reveal that the road and bridge rehabilitation project generated significant economic benefits at the community level by increasing the number of small and medium-sized enterprises and by decreasing the importance of barter trade. However, the most notable finding of their study is that the road and bridge project benefited the poor and the non-poor differently. The non-poor benefited more in terms of improved access to emergency medical assistance and in greater opportunities for non-agricultural employment. The poor, however, benefited more in terms of increased female off-farm employment and increased sales of agricultural products. 
The study by Khandker et al. (2009) corroborates the findings of $\mathrm{Mu}$ and van de Walle (2007) that rural roads can contribute to poverty alleviation by providing access to markets and human capital facilities. However, in contrast to Mu and van de Walle (2007), Khandker et al. (2009) further extend the idea that the poverty effects of road investments can differ by household type.

The authors first assess the impacts of two road projects in Bangladesh (RDP and RRMIMP) ${ }^{3}$ on a range of household outcomes ${ }^{4}$ using householdlevel panel data. They apply a fixed effect estimation approach to control for heterogeneity among households and among communities. The results reveal that rural road infrastructure can promote poverty reduction through higher prices of agricultural products (which increased by 4-5\%), lower input prices and transportation costs (fertilizer prices fell $5 \%$ and transportation costs decreased by 36-38\%), higher men's agricultural wages (which increased $27 \%$ in RDP villages only) and increased agricultural production (which rose by 30-38 \%). The authors further observe that road development, by supporting an increase in demand for labour, can generate benefits for households beyond those outlined earlier. Higher agricultural wages, brought about by an increase in demand for labour, increased household labour supply in RDP villages(male monthly employment hours rose by $49 \%$ and female monthly employment hours rose by $51 \%$ ). However, no similar statistically significant results for household labour supply were found for RRMIMP villages.

In addition, Khandker et al. (2009) find that road development led to a statistically significant increase in annual per capita consumption of $11 \%$ in both project villages and to an increase in the school participation rate for boys (which climbed by 14-20\%). While the schooling of girls also increased significantly in RRMIMP villages (14\%), this estimate, although positive, was barely significant in RDP villages.

Looking at the distribution of benefits resulting from improved road infrastructure, Khandker et al. (2009) find that gains in consumption accrue disproportionately to the very poor, but only in RRMIMP villages. For the RRMIMP sample, the consumption benefits of road investment primarily accrue to the poorest households, i.e. those below the 15 th percentile of the overall distribution. For the RDP sample, consumption benefits are significant and positive in all quintiles and average about $12-16 \%$ in each quintile.

Finally, the authors estimate the poverty reduction effect of road infrastructure projects and find it to be significant. Their findings suggest that road infrastructure projects have the potential to reduce poverty by $5-7 \%$.

\footnotetext{
${ }^{3}$ Rural Development Project (RDP) and Rural Roads and Markets Improvement and Maintenance Project -II (RRMIMP). The first phase of the RRMIMP survey (RDP) collected benchmark information on 872 households from 18 villages during May-September 1997, and the second phase (RRMIMP) covered the same households over August 2000-February 2001.

${ }^{4}$ The outcomes of interest include variables such as household transport expenses, fertilizer prices, male agricultural wages, agricultural output, male and female labour supply, and boys' and girls' schooling (5-17 years: HH average).
} 
Fan and Zhang (2008) is another study which provides evidence on the importance of the market access channel in alleviating poverty in poor countries. The study builds on the conceptual framework and modelling approach developed previously in Fan et al. (2002). Using a full information maximum likelihood technique applied to a simultaneous equations model, the authors examine the various channels through which government expenditures on rural roads affect rural poverty and agricultural production in Uganda.

Similar to the findings of the Fan et al. (2002) study conducted for the case of China, the results reveal that agricultural labour productivity and non-farm employment are significant factors determining the extent of rural poverty in Uganda. Fan and Zhang's (2008) estimates suggest that a $1 \%$ increase in agricultural production or non-farm employment would lift about $0.27 \%$ of the rural poor out of poverty. However, higher rural wages were found to have no statistically significant effect on rural poverty, which the authors argue may be due to the presence of surplus rural labour in Uganda.

Fan and Zhang (2008) examine the poverty impacts of road infrastructure by analyzing the marginal returns to public investment of different types of roads. Their calculations indicate that, among the different types of roads, feeder (dirt) roads have the largest impact on poverty reduction across Uganda, such that an additional million shillings invested in building feeder roads would allow 33 persons to escape poverty in Uganda. For murram (gravel) and tarmac (tarred) roads, the authors estimate that nine persons would be able to rise above the poverty line for each additional million shillings spent on these roads.

Fan et al. (2002) carry out a similar study using Tanzanian household level data. Their calculations of marginal returns to public investment in road infrastructure indicate that for every shilling invested, household income rises by 9.13 shillings. The authors also estimate that for every one million shillings invested in roads, on average, 27 persons are lifted out of poverty. Road investments are also found to have the largest poverty impacts in the Central and Western regions of Tanzania and in the South Highlands, where each million shillings spent on roads leads to 60-75 persons exiting poverty.

An increasing number of empirical studies seem to support the idea that strong complementarities exist between investments in road infrastructure and investments in other sectors of the economy, particularly in education. Jalilian and Weiss' (2004, p. 3) research provides evidence of a positive relationship between infrastructure and economic growth, with the caveat that this relationship is only significant in the presence of human capital development.

Jalilian and Weiss (2004) derive this finding based on their study on the impact of road infrastructure ${ }^{5}$ on economic growth and poverty across a sample of developed and developing countries. The authors apply a range of estimation techniques to find that the road infrastructure variable on its own is insignificant in all estimations. Rather, the findings reveal the existence of complementarity between

\footnotetext{
${ }^{5}$ As proxied by length of road per capita.
} 
road infrastructure and human capital, ${ }^{6}$ as captured through an interactive term. In all reported regressions, this interactive term is found to be negative and highly statistically significant.

The authors' preferred panel instrumental variable fixed effect (PIVFE) technique yields an elasticity of poverty with respect to infrastructure or human capital of -0.35 , when poverty is defined as $\$ 1$ US per day. This elasticity is -0.53 for the $\$ 2$ US per day poverty line.

Furthermore, the authors find that the poverty elasticity with respect to infrastructure (human capital) varies directly with human capital (infrastructure). Specifically, Jalilian and Weiss (2004) show that, in the case of a \$1 US a day poverty line, a $25 \%$ increase in secondary school enrollment rates raises the poverty elasticity with respect to road infrastructure from -0.35 to -0.38 . An increase in secondary school enrollment of $50 \%$ and $75 \%$ raises this elasticity further to -0.40 and -0.45 , respectively. In the case of the $\$ 2$ US a day poverty line, the elasticity is even larger, and ranges from -0.60 for a $25 \%$ increase in secondary school enrollment to -0.74 (for a $75 \%$ increase).

Balisacan and Pernia (2002) also show the importance of complementarity between public investments in infrastructure and human capital. In fact, using provincial level data for the Philippines from the 1980s and 1990s, their estimates show that road infrastructure, as measured by concrete-equivalent roads per square kilometer, can in fact significantly reduce the welfare of the poor, unless complemented by investments in human capital. As stated by Balisacan and Pernia (2002, p. 16), providing access to markets and information alone may "exert an adverse impact on the poor through such channels as factor-market and politicaleconomy processes." Only when road infrastructure is coupled with human capital (measured as the mean years of schooling of household heads), do the authors find that the welfare of the poorest improves, such that a $1 \%$ improvement in roads and schooling results in a $0.11 \%$ increase in the mean consumption expenditures of the bottom $20 \%$ percent of the population.

\section{Empirical Studies on the Impacts of Irrigation Infrastructure on Growth and Poverty}

According to the empirical literature, irrigation infrastructure can also contribute positively to reducing poverty in developing countries, both directly and indirectly. Hussain and Hanjra (2004, p. 12) provide a comparative review of recent research on the relationship between irrigation infrastructure and poverty and find that "irrigation is a positive determinant of income, a negative determinant of poverty and households having access to irrigation (and complementary inputs) are less likely to be poor."

\footnotetext{
${ }^{6}$ As proxied by secondary school enrollment.
} 
Furthermore, their review of the quantitative evidence finds that the incidence of poverty is $20-30 \%$ lower in irrigated regions of Asia than in rainfed regions. This is because, as Hussain and Hanjra (2004) observe, irrigated areas tend to have higher cropping intensity and crop productivity, and are thus more likely to exhibit higher labour productivity, employment and household incomes than rainfed areas.

In the case of China, Fan et al. (2002) find that irrigation infrastructure directly contributes to the growth of the agricultural sector, and hence, to poverty alleviation. Specifically, Fan et al. (2002) find that the elasticity of agricultural GDP with respect to irrigation infrastructure (both in per capita terms) equals 0.41 and is statistically significant.

Based on the estimated returns to public investment in irrigation, their findings demonstrate that road infrastructure exerts a stronger poverty-reducing effect than irrigation infrastructure. Namely, for every 10,000 additional yuan invested in irrigation infrastructure, 1.33 poor persons are lifted above the poverty line compared with 3.22 for road investment. This, as the authors explain, may be due to the observation that "irrigation affects poverty reduction solely through improved agricultural productivity" Fan et al. (2002, p. 45).

Balisacan and Pernia (2002) illustrate that irrigation infrastructure directly improves the welfare of the poor in Indonesia. Their estimates show that a $1 \%$ increase in the proportion of irrigated farm area to total farm area leads to a $0.23-0.31 \%$ increase in the mean per capita consumption expenditures of the bottom $20 \%$ of the population. Interestingly, Balisacan and Pernia (2002) find that the irrigation infrastructure variable is positive and statistically significant on its own (i.e. without being complemented by other investments, such as in human capital) in contrast to their findings regarding road infrastructure. This finding suggests that investments aimed at improving the quality of land may be more effective in reducing poverty in land-scarce, labour-abundant developing countries.

Huang et al. (2005) conduct a comprehensive study on the impact of irrigation infrastructure on rural incomes, poverty and the income distribution. They use data from a randomly selected, almost nationally representative sample of 60 rural villages in six Chinese provinces.

The study confirms previous studies' findings that irrigation has a strong role to play in poverty alleviation. Namely, Huang et al. (2005) find that the incidence of poverty would fall by $1.6 \%$ points if all non-irrigated agricultural land were irrigated. This translates into 12 million fewer persons living in poverty. In addition, Huang et al. (2005) show that irrigation infrastructure (measured as irrigated land per capita) increases annual per capita household income through its positive effect on cropping income. In fact, cropping income derived from irrigated land is found to have the largest marginal effect on reducing income inequality in rural China, such that a $1 \%$ increase in total cropping income from irrigated land would decrease the Gini income coefficient by $0.1 \%$.

Bhattarai and Narayanamoorthy (2003) provide additional evidence of the positive impact of irrigation on poverty alleviation. Their study shows that among all the variables included in the analysis, irrigation infrastructure had the strongest 
influence in reducing poverty in India over 1970-1994 (an elasticity of -0.37), and this impact was twice as large as that of rural poverty.

As in the case of road infrastructure, empirical evidence demonstrates the importance of complementarity between public investments in irrigation infrastructure and human capital. For example, van de Walle's (2000) study of irrigation infrastructure in Vietnam finds that strong complementarities exist between returns to irrigation infrastructure and human capital, as measured by adult attainment of primary education. His estimates suggest that increasing the primary schooling of all household heads by five full years (and that of other adults by one standard deviation) would lead to crop incomes being $36 \%$ higher on irrigated farms than on non-irrigated farms. His simulation results also show that the benefits of higher human capital would largely accrue to the poorest persons living in irrigated areas.

\section{Empirical Studies on the Impacts of Electricity on Growth and Poverty}

Empirical studies on the impact of electricity infrastructure on growth and poverty alleviation is relatively limited, compared to the abundance of literature studying road or irrigation infrastructure. The existing studies, however, provide mixed findings on the impact of electricity infrastructure on poverty.

Fan et al. (2002) find that electricity infrastructure exerts no statistically significant effect on either agricultural labour productivity or non-agricultural labour productivity in China. It also has an insignificant impact on rural non-farm wages. However, electricity infrastructure is found to contribute significantly to non-farm employment growth, and ranks better in its poverty impact than investments in irrigation infrastructure. Specifically, for every additional 10,000 yuan spent on electricity infrastructure, 2.3 people are brought above the poverty line, compared to 1.3 persons for the case irrigation infrastructure. As the authors explain, these results may be explained by the fact that access to electricity is important for the expansion of the non-agricultural sector.

On the other hand, Balisacan and Pernia (2002) show that access to technology (as proxied by the proportion of households with access to electricity) has no statistically significant impact on the welfare of the poor in the Philippines. What is more, access to electricity coupled with human capital is still found to yield an insignificant result in all regressions. However, an analysis of the differential impact of electricity infrastructure shows that richer households tend to benefit more from access to electricity than the poor. Namely, a $1 \%$ increase in the proportion of households with access to electricity improves the welfare of the third and the fourth quintile by $16.2 \%$ and $14.4 \%$, respectively. In contrast, the first and the second quintiles see a $4.9 \%$ and $9.8 \%$ improvement in their welfare, respectively.

In contrast, based on Ugandan data, Deininger and Okidi (2002) find that access to key public goods, such as electricity, critically determine households' ability to increase its income and to reduce the risk of falling into poverty. Their results show that households with access to electricity had higher incomes (3.5 percentage 
points) and expenditures (6 percentage points) than those who had no such access. In addition, multinomial log it regressions show that households with electricity access had a $20 \%$ higher chance of not falling into poverty than those that did not. As Deininger and Okidi (2002) explain, this effect most likely emerges due to the indirect effects of electricity availability (e.g. higher demand for labour) which reduce households' vulnerability to poverty.

\section{Empirical Studies Using an Aggregate Index of the Infrastructure Stock}

While the empirical literature reviewed earlier tended to use various proxies for infrastructure, several studies have attempted to quantify the overall effect of infrastructure on growth and poverty by constructing an aggregate index of the infrastructure stock. Some examples of these studies are Calderon and Serven (2004), Calderón and Chong (2004) and Sahoo and Dash (2009).

Calderon and Serven (2004) construct an aggregate index of the quantity of infrastructure using three independent, physical measures of infrastructure: the number of main telephone lines per 1,000 workers, the electricity generation capacity of the economy in MW per 1,000 workers and the length of the road network $\left(\mathrm{km}\right.$ roads $/ \mathrm{km}^{2}$ of land area). The authors also construct an aggregate index of infrastructure quality using information on the waiting time for telephone main lines in years, the percentage of transmission and distribution losses in the production of electricity and paved roads as a share of total roads.

Using panel data from 1960 to 2000 for a large sample of developed and developing countries, Calderon and Serven (2004) find that the quantity of infrastructure has a robust positive effect on growth, all else equal, and a one standard deviation increase in the stock of infrastructure raises the economic growth rate by 3 percentage points. The quality of infrastructure is also found to have a positive, albeit less empirically robust, growth effect. In this case, a one standard deviation increase in the quality of infrastructure raises the economic growth rate by 0.68 percentage points, but this effect is only significant in their preferred GMM-IV estimation technique.

Furthermore, Calderon and Serven (2004) find that both the quantity and quality of infrastructure have a robust negative effect on income inequality. Here, one standard deviation increase in the infrastructure quantity index reduces the Gini coefficient by 0.06 , while an analogous increase in the infrastructure quality index reduces the Gini coefficient by 0.01 . These results lead the authors to conclude that "infrastructure development may be a key win-win ingredient for poverty reduction" (Calderon and Serven 2004, p. 26).

Calderón and Chong (2004) provide further evidence that the quantity and quality of infrastructure are both negatively related to income inequality. Using physical measures of roads, railways, telecommunications and energy, they also construct indices for both the quantity and quality of infrastructure. They apply the GMM-IV difference estimator to panel data spanning from 1965 to 1995 for sample of developed and developing countries. Their results show that the quantity of 
infrastructure has a larger impact on reducing income inequality in developing countries than in developed countries, while the inequality-reducing effect of infrastructure quality is larger for developed countries.

Sahoo and Dash (2009) develop an index of infrastructure quantity to estimate its impact on economic growth in India over 1970-2006. Their infrastructure index incorporates six measures: per capita electricity power consumption, per capita energy use, telephone lines (both fixed and mobile) per 1,000 people, rail density per 1,000 people, air transport, freight in megatons per kilometer and paved roads as a share of total roads.

The authors estimate three production functions which all include the infrastructure stocks index as an input factor alongside varying private inputs. The results show that the long-run output elasticity of infrastructure is positive and statistically significant in all cases, and ranges from 0.24 to 0.35 . Interestingly, their results reveal that the output elasticity of the infrastructure index is higher than that of private capital and total real investment, implying that infrastructure has contributed more strongly to economic growth in India than either of these two variables.

\section{Education in Growth Models}

The importance of human capital in facilitating economic growth and in raising living standards is widely recognized in policy and academic circles. Education is a primary source of human capital. In fact, as Aghion and Howitt (1998, p. 355) write, "education requires human capital as an input as well as producing it as an output." At the same time, ideas and inventions, which arise from human capital accumulation, are directly related to the pace of economic growth. Education thus provides an important foundation for both public and private strategies to develop human capital.

At the theoretical level, there exists strong support for education as a key factor driving economic growth. Endogenous growth models as pioneered by the works of Nelson and Phelps (1966) and Lucas (1988) provide valuable insights into the mechanisms through which education promotes economic growth and development. On the one hand, education increases the skills and capacity of workers as a production factor, and on the other hand, confers a series of positive externalities that start a "ripple effect" throughout the economy.

\section{Theoretical Considerations}

As Aghion and Howitt (1998) observe, there are two common approaches to modelling education within theoretical endogenous growth models: Lucas and Nelson-Phelps-type modelling. The first modelling approach presents an extension of the neoclassical Solow model, with the concept of capital broadened to include 
human capital accumulation. Within this approach, accumulated human capital enters into the production of goods and services as a factor input and is the primary source of sustained economic growth.

In contrast, the second modelling approach is explicitly concerned with the indirect contribution of human capital to output. In these theoretical models, the level of human capital stocks can stimulate economic growth via technological change. In particular, a higher level of human capital at a given point in time (rather than a given rate of change as in Lucas) can increase growth either though new innovation (e.g. Romer 1990) or old innovation (Nelson and Phelps 1966).

\section{Lucas-Type Modelling of Education}

Lucas (1988) builds an endogenous growth model that includes human capital accumulation as an additional factor input in the aggregate production function of an economy. He specifies Cobb-Douglas technology with constant scale returns to individual human capital $h$ and private capital $k$ (with shares given by $l-\alpha$ and $\alpha$, respectively). The technology also includes a term for economy-wide average human capital, $H$ :

$$
y=A k^{\alpha}(u h)^{1-\alpha} H^{\gamma}
$$

The economy considered by Lucas (1998) is composed of infinitely-lived individuals who, at any given point in time, decide to use a fraction $u$ of their time to work and a fraction $(1-u)$ to acquire education, which is the primary method to accumulate human capital. The law of motion for human capital is:

$$
\dot{h}=\delta h(1-u)
$$

where $\delta>0$ is a parameter which denotes human capital productivity. Since human capital accumulation is specified as a linear function of the level of human capital, human capital is an engine of growth in the Lucas (1988) model. In the steady state, output and human capital grow at the same rate, and depend on $\delta$ and the equilibrium value of $u$. This can be observed from the solution to the representative consumer's intertemporal utility maximization problem:

$$
g=\delta\left(1-u^{*}\right)
$$

As noted by Aghion and Howitt (1998), time spent on education can be shown to depend negatively on the time preference rate $\rho$ and the coefficient of relative risk aversion $\sigma$, and positively on the productivity of schooling $\delta$, such that:

$$
g=[(1-\beta+\gamma)(\delta-\rho)] /[\sigma(1-\beta+\gamma)-\gamma]
$$




$$
1-u^{*}=[(1-\beta)(\delta-\rho)] / \delta[\sigma(1-\beta+\gamma)-\gamma]
$$

This model provides the basis for Lucas' (1988) main argument that economic growth is sustainable in the long run if growth in human capital continues without limit. Sustained growth is achievable in the Lucas (1998) model due to the assumption of constant returns to accumulated human and private capital, irrespective of the numerous externalities generated by human capital. Specifically, the model generates positive growth even in the absence of externalities $(\gamma=0)$, since longrun growth depends on private and human capital investments which (presumably) generate constant returns to human and private capital accumulation. In the presence of positive externalities $(\gamma>0)$, there are increasing returns to all factors of production. This possibility, as discussed in Aghion and Howitt (1998), suggests that individuals and firms would tend to underinvest in education if it were left to the free market.

In contrast to Lucas (1988), Tamura (1991) excludes the human capital externality parameter from the aggregate production function, and instead introduces it into the human capital accumulation equation:

$$
\begin{gathered}
y=A k^{\alpha}(u h)^{1-\alpha} \\
\dot{h}=\delta[h(1-u)]^{\beta} H^{1-\beta}
\end{gathered}
$$

Thus, economy-wide average human capital $H$ represents an input into the production of individual human capital $h$. This allows Tamura's (1991) model to correspond better with the idea that individuals learn from the knowledge of others. The economy can sustain long-run growth only if $\beta$ is less than 1 .

Furthermore, Tamura's (1991) model suggests that individuals with belowaverage human capital gain the most from education by the externality effect, relative to individuals with above-average human capital. Tamura (1991) writes that individuals with low levels of human capital can acquire existing knowledge, while individuals with the highest level of human capital are most likely already at the 'frontier of knowledge'. Thus, the human capital of individuals with belowaverage human capital grows faster than that of individuals with above-average human capital, such that "an initially heterogeneous population converges to a homogenous population" (Tamura 1991, p. 524). If such a knowledge spillover effect exists across regions, or even countries, then Tamura's (1991) model implies that convergence in terms of both the growth rates of income and the level of per capita income can be achieved without mobility of any of the production factor inputs.

In contrast to Lucas (1988) and Tamura (1991), Rebelo's (1991) model does not give rise to knowledge externalities. In Rebelo's (1991) model, production is characterized by Cobb-Douglas technology and combines a fraction $(\varphi)$ of the private capital stock with $\mathrm{NH}$ efficiency units of labour, which arises from $N$ hours of work combined with $H$ units of human capital: 


$$
Y=A_{1}(\varphi K)^{1-\gamma}(N H)^{\gamma}
$$

Furthermore, in contrast to Lucas (1988), Rebelo (1991) introduces private capital into the human capital accumulation equation, while retaining the assumption of constant returns to the accumulation of human and private capital stocks. Each worker has one unit of time in each period and consumes $L$ hours of leisure, which are exogenously specified. The remaining $1-L-N$ hours are devoted to accumulating human capital and generate $(1-L-N) H$ efficiency units of labour. Human capital depreciates at rate $\delta$ and is produced according to the following equation:

$$
\dot{H}=A_{2}[K(1-\varphi)]^{1-\beta}[(1-L-N) H]^{\beta}-\delta H
$$

An interesting property that arises from Rebelo's (1991, p. 510) model is that the steady-state growth rate of the economy increases in the total number of hours worked and in the total number of hours devoted to human capital accumulation, implying that the "economies with hard-working agents will grow faster".

In further contrast to Lucas (1988), Rebelo (1991) shows that the income tax rate can affect the steady-state growth rate when private capital is introduced as an input into the human capital accumulation equation. In this case, higher income taxes lower the long-run growth rate of the economy.

Both Lucas (1988) and Rebelo (1991) assume that an individual's return to education remains constant regard less of the initial level of human capital. However, the return may not be constant over an individual's lifetime as suggested in Becker (1964). Azariadis and Drazen (1990) reformulate the Lucas (1988) model within an OLG framework to deal with the issue of variable returns over an individual's life time. The authors assume that there exists an intergenerational externality to education, such that the present generation of individuals inherit the aggregate human capital accumulated by the previous generation of individuals. Following Aghion and Howitt's (1998) exposition of Azariadis and Drazen's (1990) model, the human capital accumulation equation is specified as:

$$
h_{2, t}=\left(1+\gamma\left(v_{t-1}\right) v^{\theta}\right) h_{1, t}
$$

where $\mathrm{h}_{2, \mathrm{t}}$ is the accumulated human capital of an old individual born at date $\mathrm{t}$, and $\mathrm{h}_{1, \mathrm{t}}$ is the accumulated human capital of a young individual born at date $\mathrm{t}, \mathrm{h}_{1, \mathrm{t}}=\mathrm{h}_{2}$, $\mathrm{t}-1$. The fraction of time allocated to education by a young individual born at date $t$ is denoted as $v$ and $v_{\mathrm{t}-1}$ is the amount of time devoted to education by the previous generation.

The central idea put forth by Azariadis and Drazen (1990) is that the positive externalities generated by human capital may give rise to the possibility of two locally stable balanced growth paths. One path is described as an "underdevelopment trap" and is characterized by low labour quality and zero growth in per capita income. An economy could fall into an underdevelopment trap if previous 
generations did not invest sufficiently in education, thereby curtailing the acquisition of skills by future generations and their investment in education. However, if the education investment of the previous generation was sufficiently high, individuals in subsequent generations will also invest more in education and thereby contribute to future growth. This is the high-growth path which exhibits higher labour quality and positive growth.

The intuition behind this result is that economies that find themselves in an "underdevelopment trap" have very low initial stocks of human capital, such that the marginal return to investments in education is less than the opportunity cost of withdrawing resources from goods production. Consequently, growth in the stock of human capital remains stagnant as does growth in per capita incomes. In contrast, economies on a high-growth path are characterized by a larger initial stock of human capital, such that the returns to investments in education are sufficiently high to continue spending on education. As a result, the economy follows a balanced growth path with a constant human-to-physical capital ratio and exponential per capita income growth.

Despite a strong theoretical case for a causal link running from education to economic growth, recent theoretical studies have strived to explain why higher public investment in education may not necessarily always lead to higher growth. These studies suggest that the positive effect of higher public investment in education can be diminished or even negated via general equilibrium effects when other economic factors which impact human capital accumulation are considered.

A theoretical study carried out by Teles and Andrade (2008) looks into the impacts of government investment in basic education on both individual investments in higher education and economic growth within an overlapping-generations framework. Their study aims to explain why some countries with high levels of public investment in basic education grow slowly. They find that countries with high public spending on basic education with little or no investment in higher education may grow slowly as income taxation can distort an individual's incentive to invest in higher education.

They arrive at this result by first constructing a model that includes no government involvement in education and then compare its results to those derived from a model that includes the government. Teles and Andrade (2008) consider individuals which live for three periods, and who consume in the second and third periods, respectively according to the following equations:

$$
\begin{gathered}
c_{t}=\left(1-h_{t}\right) H_{t} \\
c_{t+1}=H_{t+1}
\end{gathered}
$$

where $c$ is the individual's consumption, $h$ is the number of hours dedicated to human capital accumulation and $H$ is the individual's initial stock of human capital. The individual's human capital stock in period $t+l$ is given by: 


$$
H_{t+1}=h_{t}+H_{t}
$$

In this model, the production function is given by multiplying the number of hours worked by the individual's human capital stock. In the first period, the individual chooses the number of hours to allocate to work and to human capital accumulation in order to maximize an intertemporal utility function. The individual's maximization problem is:

$$
\operatorname{Max}_{h}\left(\frac{[(1-h) H]^{1-\theta}-1}{1-\theta}\right)+\beta\left(\frac{(h+H)^{1-\theta}-1}{1-\theta}\right)
$$

where $H \equiv H_{t}$ and $h \equiv h_{t}$. The individual's optimal choice of $h$ is given by:

$$
h=\frac{\beta^{(1 / \theta)} H^{(\theta-1) / \theta}-H}{1+\beta^{(1 / \theta)} H^{(\theta-1) / \theta}}
$$

This result shows that for low risk aversion $(\theta<1)$, the amount of hours that individuals devote to accumulating human capital is positively related to his or her initial human capital stock. Teles and Andrade (2008, p. 356) emphasize the importance of this result: "the more human capital an individual accumulates during childhood, the more time this individual will allocate towards accumulating human capital in adulthood." This finding further implies that governments should focus on investing in basic education to encourage individuals to invest in education during their adult life.

When the government is included in the model, the initial human capital stock becomes a function of government investment in basic education as a share of GNP $(\varepsilon)$ is:

$$
H=\varphi \varepsilon
$$

where $\varphi>0$ is constant and represents the marginal productivity of government investment with regard to the human capital stock. The government finances investments in basic education through a flat tax rate on the income of individuals; in periods 2 and 3, i.e. $\varepsilon=\tau$. The individual's consumption in each period is then given by:

$$
\begin{gathered}
c_{t}=[(1-h) \varphi \varepsilon](1-\varepsilon) \\
c_{t+1}=[\varphi \varepsilon+h](1-\varepsilon)
\end{gathered}
$$

The solution to the utility maximization problem then becomes: 


$$
h=\frac{(\beta / \varphi \varepsilon)^{(1 / \theta)} \varphi \varepsilon-\varphi \varepsilon}{1+(\beta / \varphi \varepsilon)^{(1 / \theta)} \varphi \varepsilon}
$$

This result points to the finding that when $\theta<1$, the number of hours spent on accumulating human capital is negatively related to government spending on basic education, which seems to contradict the result obtained earlier. This is because government investment in basic education is financed by a tax on the adult generation, crowding out private investment in education.

The authors define the workers' average level of schooling as:

$$
H_{a}=\frac{\varphi \varepsilon+(\varphi \varepsilon+h)}{2}
$$

Since population size is held constant, Teles and Andrade (2008) find economic growth to be proportional to the increase in the average level of schooling of workers:

$$
\frac{\dot{Y}}{Y}=\frac{\dot{H}_{a}}{H_{a}}=\frac{\left[\varphi+\left(\frac{1}{2}\right)\left(\frac{d h}{d \varepsilon}\right)\right]}{[\varphi \varepsilon+(h / 2)]} \dot{\varepsilon}
$$

Theoretically, this result makes it impossible for the authors to affirm that an increase in government investment in basic education would necessarily increase the average number of years of schooling and, hence, economic growth. In fact, when the authors consider decreasing returns to the human capital stock and its accumulation $(\theta<1)$, the average level of schooling increases by less than government investment in education, which suggests a possible negative or negligible relationship between public education investment and economic growth. The authors suggest that such a relationship may arise because the income taxation needed to finance high levels of government investment in basic education distorts individual's incentives to pursue higher education.

Sequeira and Martins (2008) analyze the effects of government education subsidies in an endogenous growth model with human capital accumulation and unemployment. Intuitively, the results of their theoretical exercise show that subsidies directly enhance growth through human capital accumulation, but also increase equilibrium wages, leading to higher unemployment. Hence, subsidies through their negative effect on unemployment decrease the productivity of human capital accumulation and thereby deter growth. Moreover, education subsidies are also found to have negative impacts through related taxation. This leads the authors to determine the conditions under which subsidies stimulate economic growth, conditional on the level of unemployment.

Sequeira and Martins (2008) consider an economy populated by P individuals, each endowed with $h$ human capital units and one unit of time supplied in elastically. The total level of human capital is given by: 


$$
H=h P
$$

The production technology has a Cobb-Douglas form:

$$
Y=K^{\alpha} H^{1-\alpha} L^{1-\alpha}
$$

where $L$ stands for the employment rate as all individuals are assumed to belong to the labour force. The human capital accumulation equation depends positively on employment as follows:

$$
\dot{H}=(b L) I_{S}-\delta H
$$

where $I_{S}$ denotes education investments and parameter $b$ measures its efficiency. Employment can also be defined as $(1-u)$, where $u$ is the unemployment rate.

Individuals maximize a CES utility function subject to:

$$
Y=C+I_{S}+I_{K}-s I_{S}+t Y
$$

where sis the subsidy rate, i.e. the percentage of spending on education financed by the government.

Solving the consumer optimization problem and combining it with the profit maximization problem, Sequeira and Martins (2008) obtain the following equilibrium human-to-physical capital ratio:

$$
\left(\frac{H}{K}\right)^{*}=\frac{b L}{\alpha} \frac{(1-\alpha)}{(1-s)}
$$

This equation specifies the first effect of subsidizing education: it increases the equilibrium human-to-physical capital ratio. Assuming that subsidies are financed by a tax on output $\left(t=s I_{S} / Y\right)$ and based on the derived consumption growth equation, the authors obtain the following steady-state growth rate:

$$
g_{C}^{*}=\frac{1}{\theta}\left[\frac{Y-s I_{s}}{Y} \alpha^{\alpha}(1-\alpha)^{1-\alpha}(1-s)^{-(1-\alpha)} b^{1-\alpha}(1-u)^{2(1-\alpha)}-\rho-\delta\right]
$$

The authors distinguish two opposite effects of subsidies in this equation, for a given level of unemployment: a negative one $\left(-\mathrm{sI}_{\mathrm{S}} / \mathrm{Y}\right)$ and a positive one $(1-$ s) ${ }^{-(1-\alpha)}$. Stating government education subsidies as a share of GDP $\left(\frac{s I_{S}}{Y}\right)$, yields:

$$
g_{C}^{*}=\frac{A(1-s)^{\alpha-1}(1-u)^{2(1-\alpha)}-\left(\frac{1-\alpha s}{1-s}\right) \delta-\rho}{\theta+(1-\alpha) \frac{s}{1-s}}
$$

This equation describes the partial (i.e. given unemployment) relationship between education subsidies and economic growth. Sequeira and Martins (2008) 
use this relationship to show that, under certain parameters/conditions, subsidies increase economic growth conditional on unemployment, where unemployment negatively impacts the effect of education subsidies on growth. More specifically, Sequeira and Martins (2008, p. 366) write:

For sufficiently low subsidies rate, $s<\frac{\theta-1}{\theta-1+\alpha^{\prime}}$, and sufficiently low depreciation of capital $\rho>(\theta-1) \delta$, there is a positive effect of subsidies on economic growth rate, given the unemployment rate. Given that the partial effect of subsidies on growth is positive, the impact of higher unemployment is negative in that effect. This means that rising unemployment decreases the positive effect subsidies may have on growth.

\section{Nelson-Phelps-Type Modelling}

While Lucas (1988) considers a broad definition of human capital, in the sense that it can encompass the accumulation of knowledge and abilities to apply knowledge productively, Nelson and Phelps (1966) consider a more narrow human capital concept by specifically focusing on the impact of education on technological change. As Aghion and Howitt (1998, p. 338) write, "Nelson and Phelps (1966) provided a first attempt at modelling the idea that a major role for education is to increase the individual's capacity, first, to innovate (i.e. to create new activities, new products, new technologies) and, second, to adapt to new technologies, thereby speeding up technological diffusion throughout the economy."

In the approach of Nelson and Phelps (1966), education has a permanent effect on technological change and this effect drives sustained long-run growth. According to Nelson and Phelps (1966), the Lucas (1988) approach to modelling education as a direct factor of production amounts to "a gross misspecification of the relation between education and the dynamics of production" (Nelson and Phelps 1966, p. 75). Instead, Nelson and Phelps (1966) propose that education exerts an indirect effect on the production function of an economy through the rate of technological change.

A rising stock of human capital benefits growth by supporting the economy's ability to innovate and adopt new technologies. This implies that differences in the levels of human capital (instead of differences in the growth rates of human capital as suggested by Lucas (1988)) cause differences in output growth across countries. Hence, unlike in Lucas (1988), the growth rate of an economy depends on the level of technology $A$, and the growth rate of technology depends on the stock of human capital, which is viewed as a key input in the generation of new ideas and innovations. For any given country, Nelson and Phelps (1966) specify the following technological growth equation:

$$
A(t)=\Phi(h)[T(t)-A(t)]
$$

where $h$ is the current human capital stock in an economy, such that $\Phi(h)$ represents educational attainment $a$ in the country. $T(t)$ denotes the frontier technology which grows over time at a constant exponential rate $\lambda, T(t)=T_{0} e^{\lambda t}$. The term $[T(t)-A(t)]$ 
represents the gap between the theoretically possible and actually used production technologies.

First, assuming exponential growth of $T(t)$ and a positive $h$, Nelson and Phelps (1966) postulate that the rate of growth in production technologies actually used in an economy, i.e. $\frac{A(\dot{t})}{A(t)}$, falls to $\lambda$ at the limit, independent of educational attainment. Second, the gap between theoretically possible and actually used technologies, in the equilibrium, is a decreasing function of educational attainment. In this way, increased educational attainment increases the long-run trajectory of technology actually used in the economy. Both of these results constitute the solution to the equation specified in Eq. 60, given exponential growth of $T(t)$ :

$$
A(t)=\left(A_{0}-\left[\frac{\Phi}{\Phi+\lambda}\right] T_{0}\right) e^{-\Phi t}+\frac{\Phi}{\Phi+\lambda} T_{0} e^{\lambda t}
$$

This implies that the equilibrium path of technology actually used in the economy is given by:

$$
A^{*}(t)=\frac{\Phi(h)}{\Phi(h)+\lambda} T_{0} e^{\lambda t}
$$

and the equilibrium gap between the theoretically possible and actually used technologies is given by:

$$
\frac{T(t)-A^{*}(t)}{A^{*}(t)}=\frac{\lambda}{\Phi(h)}
$$

Hence, in a technologically stagnant economy (defined as $\lambda=0$ ), the gap approaches zero even when $h$ is positive. In a technologically progressive economy $(\lambda>0)$, there is a positive equilibrium gap for every $h$ and $\lambda$. The equilibrium gap is increasing in $\lambda$ and decreasing in $h$. The elasticity of the long-run equilibrium level of technology actually used $A^{*}(t)$ with respect to $h$ is increasing in $\lambda$. This indicates that returns to educational attainment are greater in a more technologically progressive economy. According to Nelson and Phelps (1966, p. 75), this result suggests that "society should build more human capital relative to tangible capital the more dynamic is the technology".

As Aghion and Howitt (1998, p. 354) observe, both the Lucas and Nelson-Phelps approach to modelling education in growth model simply different long-run growth effects. Namely, education may have a growth effect (Lucas) or a level effect (Nelson-Phelps) on the economy. They write, "what is at stake is whether raising the level of human capital will have either a once-and-for-all effect on output or increase its growth rate effect forever." However, Aghion and Howitt (1998) emphasize that it is plausible for both theoretical approaches to be true, with the difference being more semantic than real. They argue that an increase in the level of 
human capital brings about an increase in output (Nelson-Phelps approach) and this is brought about through an increase in transitional growth rates (Lucas approach).

Romer (1990) presents a major extension of the Nelson-Phelps approach to modelling education within endogenous growth models. As this model is widely studied in both undergraduate and graduate macroeconomic textbooks, it will be unnecessary to reproduce the equations of the Romer (1990) model. However, there are three crucial assumptions in Romer (1990) worth stressing: constant returns to scale, free entry in the intermediate goods sector, and the non-rivalry of knowledge. The two basic equations of the Romer's (1990) model are:

$$
\begin{gathered}
Y=H_{Y}^{\alpha} L^{\beta} \int_{0}^{\infty} A x(i)^{1-\alpha-\beta} d i \\
\dot{A}=B H_{A} A
\end{gathered}
$$

where $H_{Y}$ denotes human capital devoted to final output and the $x(i)$ 's are imperfectly substitutable intermediate inputs in production. In the production function for ideas, $H_{A}$ denotes human capital employed in research, $B$ denotes the rate at which new ideas are discovered and $A$ represents the 'stock of varieties' of ideas. Thus, new ideas are produced using both human capital employed in research and the stock of earlier ideas.

Due to constant returns to scale in the research sector, the model's growth solution exhibits a scale effect such that an increase in the population growth rate increases the supply of labour in research, which in turn increases research output and hence the steady state growth rate:

$$
g_{A}=n
$$

where $n$ denotes the rate of population growth, which is equivalent to the growth rate of the number of researchers.

However, such a scale effect may not be present in developing countries. Jones (2002) disagrees with Romer's (1990) idea that the productivity of researchers grows over time, generating sustained long-run growth even if the number of researchers remains constant. He challenges the assumption of constant returns to scale in the research sector and shows that the effect of huge R\&D expenditures on growth even in advanced OECD countries is practically nil. Instead, Jones (2002) proposes the existence of diminishing returns to the stock of ideas.

The possibility of diminishing returns is considered in a recent study conducted by Papageorgiou and Perez-Sebastian (2006). The authors build an R\&D non-scale growth model that includes endogenous human capital and technological progress. They consider innovation and imitation as two of the main sources of technological progress, while formal schooling is considered as the main source of human capital.

The model economy of Papageorgiou and Perez-Sebastian (2006) consists of identical infinitely-lived individuals, and grows exogenously at rate $\mathrm{n}$. Individuals in the economy can produce consumer goods, pursue education and conduct R\&D. 
In each period, individuals allocate their one unit of time endowment between working and studying. Output is produced via Cobb-Douglas technology:

$$
Y_{t}=A_{t}^{\xi} H_{Y t}^{1-\alpha} K_{t}^{\alpha}, 0<\propto<1, \xi>0
$$

where $A_{t}$ is the economy's level of technology, $\xi$ is the technology-output elasticity, $H_{Y t}$ is human capital and $K_{t}$ is private capital.

The economy's technological level evolves according to the following equation:

$$
A_{t+1}-A_{t}=\mu A_{t}^{\varphi} H_{A t}^{\lambda}\left(\frac{A_{t}^{*}}{A_{t}}\right)^{\psi}-\delta_{A} A_{t}, \varphi<1,0<\lambda \leq 1, \psi \geq 0, A_{t}^{*} \geq A_{t}
$$

where $\delta_{A}$ represents the technology depreciation rate. $H_{A t}$ is the portion of human capital employed in the R\&D sector at time $t$. The worldwide technology frontier $A_{t}^{*}$ grows exogenously at rate $g_{A^{*}, \mu}$ is a technology parameter, $\varphi$ weighs the effect of the stock of existing technology on $\mathrm{R} \& \mathrm{D}$ productivity and $\lambda$ captures decreasing returns to $\mathrm{R} \& \mathrm{D}$ efforts.

Following Nelson and Phelps (1996), the R\&D technology equation allows for a 'catch-up' term, $\left(\frac{A_{t}^{*}}{A_{t}}\right)^{\psi}$, which captures the idea that the greater the technology gap between the most technologically advanced country and the least technologically advanced country, the higher the potential of the latter to catch up through imitation of existing technologies. The parameter $\psi$ represents the adoption barrier. Together, the production function and the R\&D technology equation reflect complementarity between technology and human capital.

In specifying the human capital technology, Papageorgiou and Perez-Sebastian (2006) follow Bils and Klenow (2000) who suggest that the Mincerian specification of human capital is the appropriate way to incorporate years of schooling into the aggregate production function. In this regard, aggregate human capital is given by:

$$
H_{j t}=e^{f(S t)} L_{j t}
$$

where $L_{j t}$ is the total amount of labour allocated to sector $j$ and $S_{t}$ is the average educational attainment of labour in period t. The derivative $f^{\prime}(S)$ represents the return to schooling estimated in a Mincerian wage regression: an additional year of schooling raises a worker's efficiency by $f^{\prime}(S)$. Average educational attainment is expressed as:

$$
S_{t}=\frac{\sum_{j=1}^{t-1} L_{H j}}{L_{t}}
$$

where $L_{t}$ denotes population size and $L_{H t}$ denotes the total amount of time allocated to schooling in period $t$. The law of motion for average educational attainment is as follows: 


$$
S_{t+1}-S_{t}=\left(\frac{1}{1+n}\right)\left(\frac{L H_{t}}{L_{t}}-n S_{t}\right)
$$

Thus, the evolution of $S$ across time depends on the share of people in education $L_{H} / L$ and the population growth rate. The steady-state solution to the model suggests that, along the balanced growth path, the economy invests in sufficient human capital to provide new generations with precisely the steady-state level of educational attainment. Moreover, the steady state growth rate of output is:

$$
G_{Y, s s}=G_{C, s s}=G_{K, s s}=(1+n)^{\lambda \xi /[(1-\alpha)(1-\varphi)]}
$$

Consistent with Jones (2002), the derived balanced growth path is free of scale effects, and policy has no effect on long-run growth. This occurs despite the presence of a formal schooling sector. This is because the mean years of education $S_{t}$ reaches a constant level in the steady state.

\section{Empirical Evidence}

The literature studying the relationship between education, growth and poverty is overwhelming. Lucas' (1988) assertion that unbounded long-run growth can be achieved as long as human capital grows infinitely has posed a challenge for applied researchers faced with interpreting such a broad concept of human capital. For the most part, applied researchers have used a variety of proxies to measure human capital such as years of schooling, enrollment ratios, school completion rates, literacy rates, and many others. One of the most commonly used measures of human capital in the empirical literature is educational attainment, or the level of education. The findings of this literature are virtually unanimous and suggest three important conclusions. First, education positively impacts growth and reduces poverty. Poverty reduction is achieved not only through education's positive impact on future earnings, but also through a wide range of non-economic benefits ranging from personal empowerment to improved health. The second consistent finding is that returns to investments in education seem to be lower than returns to other types of public investments (such as in physical infrastructure and agricultural R\&D). Thirdly, individual returns to education are much higher for those with higher levels of education.

This section reviews a selection of studies that analyze the growth and poverty impacts of education investments, especially in developing countries. It finds that the varying measures of human capital used in the empirical studies do not alter the main conclusions they reach.

Using a regional level panel dataset for 1977-1999, Fan et al. (2008) estimate the marginal returns to different types of government investments, in terms of growth and rural poverty reduction in Thailand. Their results show that public investment 
in rural primary education have the third largest impact (after investments in agricultural research and rural electrification) on agricultural productivity and poverty reduction. The return to rural primary education investments is significant, such that 4.09 Thai baht are gained for each baht invested. In terms of poverty effects, the results indicate that for every million baht invested in rural education, 77 poor persons are lifted out of poverty. The poverty effect mainly operates through the positive effect of rural education on agricultural productivity.

Using district level data for 1992, 1995 and 1999, Fan and Zhang (2008) estimate the effects of different types of government investments on agricultural growth and rural poverty in Uganda. As in the case of Thailand, they find that government investments in education rank third in their impact on agricultural productivity and poverty reduction (after spending on agricultural research and road investment).In terms of productivity effects, for the country as a whole, investments in education are estimated to have a benefit-cost ratio of 3, suggesting that each additional shilling invested at the margin would yield three shillings. In terms of its poverty impact, public investments in education are estimated to bring 12.8 poor persons out of poverty for every million shillings invested. The authors suggest that this poverty-reducing effect of education investments arises mainly from improved agricultural productivity, higher non-farm employment and increased rural wages.

Fan et al. (2000) estimate the impact of different types of government spending on agricultural growth and rural poverty reduction in India using 1970-1993 state level data. They find that government education spending has the third largest marginal impact on rural poverty and productivity growth, after investment in rural roads and agricultural research. An additional one million rupees invested in education raises 41 people above the poverty line. Greater nonfarm employment opportunities and increased wages are found to be the main factors contributing to reduced poverty. The authors also find that if the government were to increase its investment in education by Rs100 billion (at 1993 constant prices), the incidence of rural poverty would be $0.22 \%$ lower.

Using household survey data, Fan et al. (2005) carry out a similar empirical exercise for the case of Tanzania. They find that every shilling invested in education by the government leads to a nine shilling increase in average household incomes. The estimated returns to investment in education are found to rank third after investments in agricultural research and road investment. However, the poverty effect of public investment in education ranks first, with every million shillings invested bringing 43.1 persons out of poverty.

Using 1970-1997 provincial level data for the case of China, Fan et al. (2002) find that government expenditures on rural education significantly contribute to an increase in the average years of schooling of the rural population (15 years of age and older), such that for every $1 \%$ increase in government spending on rural education, the average years of schooling of the rural population increases by $0.34 \%$. Average years of schooling of the rural population is found to have a positive and significant effect on agricultural and non-agricultural productivity, rural non-farm wages and non-farm employment. The authors further find that total public investment in education had by far the largest poverty-reducing effect, such 
that for every 10,000 yuan invested, 8.8 poor people were lifted above the poverty line; this is $30 \%$ more than comparable R\&D investments, which had the second largest poverty-reducing effect. Increased rural nonfarm employment accounts for much of this poverty-reducing effect. In addition, education is found to have the second largest returns to agricultural GDP and the third largest return to both nonfarm GDP and overall rural GDP. These findings lead the authors to conclude that investment in education presents the dominant "win-win" strategy.

Psacharopoulos and Patrinos (2002) find a pattern of falling returns to education by level of economic development and level of education. Their study emphasizes that investment in education behaves very similarly to investment in physical capital. According to their figures, in developed economies, the returns to education tend to decline as education investments expand. However, private returns to higher education in low- and middle-income countries are high, at $26 \%$ and $19.3 \%$ respectively. The authors note that private returns to education are always higher than social returns because of the extent of public involvement in the education sector. In addition, among the three levels of education (primary, secondary and tertiary), primary education exhibits the highest social returns as well as the highest private returns in all low-income, middle-income and high-income economies. This is attributed to the existence of broad positive externalities relating to primary education, such as improved public health.

\section{Concluding Remarks}

This literature review has sought to assess various strategies employed in modelling infrastructure and education within the theoretical endogenous growth literature. It has also summarized empirical findings regarding the impact of education and infrastructure on economic growth and poverty alleviation, particularly in developing countries.

Overall, this literature review finds that the theoretical studies modelling infrastructure within endogenous growth models, whether as a flow or a stock variable, tend to disregard the indirect effect that infrastructure has on some measure of output via TFP. In terms of the empirical findings, it finds that most studies have examined the impact of infrastructure on economic growth and poverty alleviation through the use of individual, physical measures of infrastructure stocks. The findings of these studies demonstrate that growth and poverty impacts of infrastructure can be substantial, but they vary across different types of infrastructure capital. For instance, investments in roads and irrigation are found to have sizeable direct and indirect effects on economic growth and poverty reduction, while the impact of electricity is less clear.

In contrast to approaches to modelling infrastructure, endogenous growth theorists who model education have not only considered the direct impact of education on output by specifying human capital accumulation as a factor input, but have also considered education's indirect impact on output via technological change. The 
empirical literature in this area overwhelmingly shows that public investments in education have a positive and significant impact on growth and poverty reduction, particularly in developing countries. However, the returns to public investments in education are consistently found to be lower than the returns generated by investments in infrastructure.

Open Access This chapter is distributed under the terms of the Creative Commons Attribution Noncommercial License, which permits any noncommercial use, distribution, and reproduction in any medium, provided the original author(s) and source are credited.

\section{References}

Agenor P-R (2007) Fiscal policy and endogenous growth with public infrastrucutre. Oxf Econ Pap 60:57-87

Agenor P-R, Moreno-Dodson B (2006) Public infrastructure and growth: New channels and policy implications. World Bank Policy Research Working Paper 4064 (November), Washington, DC

Aghion P, Howitt P (1998) Endogenous growth theory. MITPress, Cambridge, MA

Ali I, Pernia EM (2003) Infrastructure and poverty reduction: What is the connection? ERD Policy Brief No. 13, Economics and Research Department, Asian Development Bank, Manila

Aschauer D (1989) Is public expenditure productive? J Monet Econ 23:177-200

Azariadis C, Drazen A (1990) Threshold externalities in economic development. Q J Econ 105 (2):501-526

Balisacan AM, Pernia EM (2002) Probing beneath cross-national averages: poverty, inequality, and growth in the Philippines, vol 7, ERD working paper series. Economics and Research Department, Asian Development Bank, Manila

Barro RJ (1990) Government spending in a simple model of endogenous growth. J Polit Econ 98 (5):103-125

Becker GS (1964) Human capital: A theoretical and empirical analysis, with special reference to education. University of Chicago Press: Chicago, IL

Bhattarai M, Narayanamoorthy A (2003) Impact of irrigation on agricultural growth and poverty alleviation: macro level analyses in India. IWMI-TATA Water Policy Program, Water policy research highlight 12, Gujarat, 7p. http://www.iwmi.cgiar.org/iwmi-tata_html/PM2003/PDF/ 12_Highlight.pdf

Bils M, Klenow PJ (2000) Does schooling cause growth? Am Econ Rev 90:1160-1183

Bose N, Haque EM, Osborne RD (2007) Public expenditure and economic growth: a disaggregated analysis for developing countries. Manch Sch 75(5):533-556

Bravo-Ortega C, Lederman D (2005) Agriculture and national welfare around the world: Causality and international heterogeneity since 1960. World Bank Policy Research Working Paper Series 3499, Washington, DC

Calderón C, Chong A (2004) Volume and quality of infrastructure and the distribution of income: an empirical investigation. Rev Income Wealth 50:87-105

Calderon C, Serven L (2004) The effects of infrastructure development on growth and income distribution, vol 3400, World bank policy research working paper. World Bank, Washington, DC

Chen B-L, Lee S-F (2007) Congestible public goods and local indeterminacy: a two sector endogenous growth model. J Econ Dyn Control 31(7):2486-2518

Deininger K, Okidi J (2002) Growth and poverty reduction in Uganda, 1992-2000: panel data evidence. World Bank/Economic Policy Research Council, Washington, DC/Kampal

Dollar D, Kraay A (2002) Growth is good for the poor. J Econ Grow 7(3):195-225 
Eicher T, Turnovsky SJ (2000) Scale, congestion, and growth. Economica 67(267):325-346

Estache A, Fay M (2009) Current debates on infrastructure policies. Working paper no 49, Commission on Growth and Development

Fan S, Zhang X (2008) Public expenditure, growth, and poverty reductionin rural Uganda. Afr Dev Rev 20(3):466

Fan S, Hazell P, Thorat S (2000) Government spending, growth and poverty in rural India. Am J Agric Econ 82(4):1038-1051

Fan S, Zhang LX, Zhang XB (2002) Growth, inequality, and poverty in rural China: the role of public investments, vol 125, Research report. International Food Policy Research Institute, Washington, DC

Fan S, Nyange D, Rao N (2005) Public investment and poverty reduction inTanzania: evidence from household survey data. DSGD discussion paper no 18, International Food Policy Research Institute

Fan S, Yu B, Jitsuchon S (2008) Does allocation of public spending matter in poverty education? Evidence from Thailand. Asian Econ J 22(4):411-430

Fanta F, Upadhyay M (2009) Poverty reduction, economic growth and inequality in Africa. Applied Econ Letters 16(18):1791-1794

Fedderke J, Perkins P, Luiz J (2006) Infrastructural investment in long-run economic growth: South Africa 1875-2001. World Dev 34(6):1037-1059

Fisher WH, Turnovsky SJ (2013) Public investment, congestion, and private capital accumulation. Econ J 108(3):399-413

Fourie J (2006) Economic infrastructure in South Africa: a review of definitions, theory and empirics. South Afr J Econ 74(3):530-556

Futagami K, Morita Y, Shibata A (1993) Dynamic analysis of an endogenous growth model with public capital. Scand J Econ 95(4):607-625

Gramlich EM (1994) Infrastructure investment: a review essay. J Econ Lit 32(3):1176-1196

Hanmer L, Naschold F (2000) Attaining the international development targets: will growth be enough? Dev Policy Rev 18(1):11-36

Hasan R, Quibria MG (2004) Industry matters for poverty: a critique of agricultural fundamentalism. Kyklos 57(2):253-264

Huang Q, Dawe D, Rozelle S, Huang J, Wang J (2005) Irrigation, poverty and inequality in rural China. Aust J Agric Resour Econ 49:159-175

Hussain I, Hanjra M (2004) Irrigation and poverty alleviation: review of the empirical evidence. Irrig Drain 53:1-15

Jalilian H, Weiss J (2004) Infrastructure, growth and poverty: some cross-country evidence. Paper prepared for ADB Institute annual conference on 'Infrastructure and Development: Poverty, Regulation and Private Sector Investment', 6 Dec 2004, Tokyo

Jones C (2002) Introduction to economic growth. 2nd ed, W.W. Norton \& Company, Inc: New York

Kalaitzidakis P, Kalyvitis S (2004) On the macroeconomic implications of maintenance in public capital. J Public Econ 88(3-4):695-712

Khandker SR, Bakht Z, Koolwal GB (2009) The poverty impact of rural roads: evidence from Bangladesh. Econ Dev Cult Change 57:685-722

Kwon E (2005) Infrastructure, growth and poverty reduction in Indonesia: a cross-sectional analysis. Paper presented at the ADBI workshop on transport infrastructure and poverty reduction, ADB, Manila, 18-22 July 2005

Lokshin M, Yemtsov R (2005) Has rural infrastructure rehabilitation in Georgia helped the poor? World Bank Econ Rev 19(2):311-333

Lopez H, Serven L (2004) The mechanics of growth-poverty-inequality relationship. The World Bank, Mimeo

Lucas RE (1988) On the mechanics of economic development. J Monet Econ 22:3-42

Mu R, Van De Walle D (2007) Rural roads and poor area development in Vietnam. World Bank Policy Research Working Paper No 4340, The World Bank, Washington, DC 
Nelson R, Phelps E (1966) Investment in humans, technological diffusion, and economic growth. Am Econ Rev 77(1/2):297-306

Ohdoi R (2007) Productive government spending, patterns of specialisation and economic growth in a small open economy. Jpn Econ Rev 58:127-146

Papageorgiou C, Perez-Sebastian F (2006) Dynamics in a non-scale R\&D growth model with human capital: explaining the Japanese and South Korean development experiences. J Econ Dyn Control 30:901-930

Park H, Philippopoulos A (2002) Dynamics of taxes, public services and endogenous growth. Macroecon Dyn 6(2):187-201

Psacharopoulos G, Patrinos H (2002) Returns to investment in education: a further update, vol 2881, Policy research working paper. Education Sector Unit, World Bank, Washington, DC

Rebelo S (1991) Long-run policy analysis and long-run growth. J Polit Econ 99(3):500-521

Richaud C, Sekkat Kh., Varoudakis A (1999) Infrastructure and growth spillovers: A case for a regional infrastructure policy in Africa. University of Brussels, Mimeo

Rioja FK (1999) Productiveness and welfare implications of public infrastructure: a dynamic two-sector general equilibrium analysis. J Dev Econ 58(2):387-404

Rivas LA (2003) Income taxes, spending composition and long-run growth. Eur Econ Rev 47 (3):477-503

Romer PM (1986) Increasing returns and long run growth. J Polit Econ 94(5):1002-1037

Romer PM (1990) Endogenous technological change. J Polit Econ 98(5):S71-S102, Part 2: The problem of development: a conference of the Institute for the Study of Free Enterprise Systems

Romp W, de Haan J (2005) Public capital and economic growth: A critical survey, EIB papers 10 (1). European Investment Bank, Luxemburg

Sahoo P, Dash RK (2009) Infrastructure development and economic growth in India. J Asia Pac Econ 14(4):351-365

Sequeira TN, Martins EV (2008) Education public financing and economic growth: an endogenous growth model versus evidence. Empir Econ 35:361-377

Tamai T (2007) Public intermediate goods, endogenous growth, and indeterminacy. Econ Model 24:683-689

Tamura RF (1991) Income convergence in an endogenous growth model. J Polit Econ 99:522-540

Teles VK, Andrade J (2008) Public investment in basic education and economic growth. J Econ Stud 35(4):352-364

Thirtle C, Xavier I, Lin L, McKenzie-Hill V, Wiggins S (2001) Relationships between changes in agricultural productivity and the incidence of poverty in developing countries. DFID report no 7946, London

Tsoukis C, Miller NJ (2003) Public services and endogenous growth. J Policy Model 25 (3):297-307

Turnovsky SJ (2004) The transitional dynamics of fiscal policy: long-run capital accumulation and growth. J Money Credit Bank 36(5):883-910

van de Walle D (2000) Are returns to investment lower for the poor? Human and physical capital interactions in rural Vietnam, vol 2425, Policy research working paper. The World Bank, Washington, DC

World Bank (1994) World development report 1994: Infrastructure for development. The World Bank, Washington, DC

World Bank (2007) World development report 2008: agriculture for development. World Bank, Washington, DC

Yakita A (2004) Elasticity of substitution in public capital formation and economic growth. J Macroecon 26(3):391-408

Zhao Z, Kanamori T (2007) Infrastructure and Regional Development in the People's Republic of China. Asian Development Bank Institute, Tokyo. http://www.adbi.org/files/dp69.prc.infra structure.regional.dev.pdf 